\title{
Response to: Modified Rockwood frailty index is predictive of adverse outcomes in elderly populations undergoing major abdominal surgery: is it a practical tool though?
}

\author{
Jorge Humberto Rodríguez-Quintero ${ }^{1}$. Jorge Luis Aguilar-Frasco ${ }^{2} \cdot$ Paulina Moctezuma-Velázquez $^{2}$. \\ Heriberto Medina-Franco ${ }^{2}$
}

Received: 26 March 2021 / Accepted: 29 March 2021 / Published online: 7 April 2021

(C) The Author(s), under exclusive licence to Springer-Verlag GmbH Germany, part of Springer Nature 2021

\section{Dear Editor,}

We have read with substantial interest the comment to our work by Youssef et al. from the University of Nottingham, in the latest issue of Langenbeck's Archives of Surgery. First of all, we would like to thank the authors for taking the time to debate our manuscript and for promoting the interest of readers toward improving surgical outcomes for the geriatric population, which, as stated in our manuscript [1], is essential due to the increases in the number of elderly patients requiring complex operations in current times.

With regard to the methodology of our work and in particular the comment on our logistic regression model and the adjustment of the variables, one of our main concerns when collecting the data and designing the project from the beginning was the heterogeneity of our patient population in terms of the intervention performed and the baseline clinical condition of our subjects. Although it is broadly known that some of the variables that were mentioned by Youssef et al. (such as intravenous fluids, oxygen desaturation, procedure length, analgesia method, surgeon skill, hemodynamic instability, and estimated blood loss and transfusions) have shown to be predictors of unfavorable outcomes in abdominal surgery, these only represent some examples of an innumerable list of factors that may need to be acquainted for to obtain an analysis

Jorge Humberto Rodríguez-Quintero huroqu90@gmail.com

1 Montefiore Medical Center/Albert Einstein College of Medicine, 3400 Bainbridge Avenue Bronx NY 10467 USA

2 Instituto Nacional de Ciencias Médicas y Nutrición "Salvador Zubirán”, Vasco de Quiroga 15 Ciudad de México México that is entirely free of confounders, which is, in essence, impossible to attain in a non-controlled study such as ours. This is thoroughly addressed in our limitations section. Perhaps a randomized controlled trial would be necessary to suffice the uncertainties of the commenter. Nonetheless, we attempted to our best capacity based on our study design to direct our attention to the modifiers that we considered to be the most important based on our patient characteristics and the outcomes that were studied in our logistic/linear regression (ICU admission, mortality, and LOS) and consider that our study attained internal validation as to our pre-determined objectives; however, it would certainly be necessary to test for external validation of our results before being able to extrapolate these findings. With regard to the concern the author has about the discussion that took place with the patients regarding their frailty scores, we are proud to certify that this was indeed addressed as part of the perioperative discussion as fully as time and clinical situation allowed. We would like to emphasize that we consider this an essential part of our study, as it represents the pure soul and purpose of our investigation: improving the quality of the care and communication provided to our patients. Next, although we did not intend to rule it out by conducting a blind or double-blind study, we believe that it is beyond a reasonable doubt to attribute the outcomes of the interventions to the objective parameters that were studied, as we think that even the healthiest of our subjects would be in a little physical capacity to consciously change their postoperative length of stay, survival, or rate of admission to a higher level of care based on observance (Hawthorne effect).

The author finally comments on the practicality of performing mRFI in the clinical setting. In our study, one of the variables we measured was the time that the provider took to perform the questionnaire, which resulted to be a mean of 
$7 \mathrm{~min}$ [1]. We believe this is a reasonable amount of time in most settings, and in our sample, it did not delay any of the further care that was provided, as on occasions the information was accurately obtained from a proxy. Although we advocate for the use of mRFI as a screening tool for frailty since it has been externally validated in prior studies [2], we agree that it should be used in conjunction with other tools to obtain an integral preoperative assessment. To our knowledge, the Rockwood clinical frailty scale that is cited by the author has not been externally validated in the preoperative setting to this date, and its diagnostic performance is known to give inaccurate scores when applied by providers with limited experience in frailty care $[3,4]$. Interestingly, a recently published multicenter prospective observational study by Pugh et al. demonstrated good levels of agreement while using this scale; however, factors that independently associated with higher ratings were also detected, indicating that personal bias existed [5]. For the moment, our group refrains from recommending its use until more data is available to support its accuracy.

Lastly, it is important to remember that frailty represents a holistic approach to the patient's condition and situation, and it must be conceptualized as a complex situation that entails both subjective and objective parameters which could be difficult to analyze and rationalize in writing.

We would like to thank Youssef et al. again for promoting this discussion that we are assured will result in nothing but an increased interest in the improvement of patient care for the geriatric population and encourage the readers to engage in projects that are relevant to this field.

\section{Declarations}

Competing interests The authors declare no competing interests.

\section{References}

1. Aguilar-Frasco JL, Rodríguez-Quintero JH, Moctezuma-Velázquez $\mathrm{P}$, Morales-Maza J, Moctezuma-Velázquez C, Pastor-Sifuentes F, Medina-Franco H (2021) Frailty index as a predictive preoperative tool in the elder population undergoing major abdominal surgery: a prospective analysis of clinical utility. Langenbecks Arch Surg 1-10. https://doi.org/10.1007/s00423-021-02128-6

2. Rockwood K, Andrew M, Mitnitski A (2007) A comparison of two approaches to measuring frailty in elderly people. J Gerontol Ser A Biol Med Sci 62(7):738-743

3. Theou O, Pérez-Zepeda MU, van der Valk AM, Searle SD, Howlett SE, Rockwood K (2021) A classification tree to assist with routine scoring of the Clinical Frailty Scale. Age Ageing. https://doi.org/10. 1093/ageing/afab006

4. Shrier W, Dewar C, Parrella P, Hunt D, Hodgson LE (2020) Agreement and predictive value of the Rockwood Clinical Frailty Scale at emergency department triage. Emerg Med J. https://doi.org/ 10.1136/emermed-2019-208633

5. Pugh RJ, Battle CE, Thorpe C, Lynch C, Williams JP, Campbell A, Subbe CP, Whitaker R, Szakmany T, Clegg AP, Lone NI (2019) Reliability of frailty assessment in the critically ill: a multicentre prospective observational study. Anaesthesia 74(6):758-764

Publisher's note Springer Nature remains neutral with regard to jurisdictional claims in published maps and institutional affiliations. 